\title{
Trauma in elderly patients evaluated in a hospital emergency department in Konya, Turkey: a retrospective study
}

This article was published in the following Dove Press journal:

Clinical Interventions in Aging

10 December 2013

Number of times this article has been viewed

\section{Hasan Kara' \\ Aysegul Bayir ${ }^{\prime}$ \\ Ahmet Ak' \\ Murat Akinci' \\ Necmettin Tufekci' \\ Selim Degirmenci' \\ Melih Azap ${ }^{2}$}

'Department of Emergency Medicine, Selçuk University, Konya, Turkey; ${ }^{2}$ Department of Emergency Medicine, Konya Numune Hospital, Konya, Turkey
Correspondence: Hasan Kara Department of Emergency Medicine, Faculty of Medicine, Selçuk University, Aleaddin Keykubat Yerleșkesi Selçuklu, Konya 42250, Turkey

Tel +905052 II 2473

Fax +90332224 4858

Email hasankara42@gmail.com
Purpose: Trauma is a common cause of admission to the hospital emergency department. The purpose of this study was to evaluate the cause of admission, clinical characteristics, and outcomes of patients aged $\geq 65$ years admitted to an emergency department in Turkey because of blunt trauma.

Materials and methods: Medical records were retrospectively reviewed for 568 patients ( 314 women and 254 men) aged $\geq 65$ years who were admitted to an emergency department of a tertiary care hospital.

Results: Trauma was caused by low-energy fall in 379 patients (67\%), traffic accident in 79 patients (14\%), high-energy fall in 69 patients (12\%), and other causes in 41 patients $(7 \%)$. The most frequent sites of injury were the lower extremity, thorax, upper extremity, and head. The femur was the most frequent fracture site. After evaluation in the emergency department, 377 patients $(66 \%)$ were hospitalized. There were 31 patients $(5 \%)$ who died. Risk of hospitalization after trauma was significantly associated with trauma to the lower extremity, thorax, and spine; fractures of the femur and rib; and intracranial injury.

Conclusion: Emergency department admission after trauma in patients aged $\geq 65$ years is common after low-energy falls, and most injuries occur to the extremities. It is important to focus on prevention of falls to decrease the frequency of trauma in the elderly.

Keywords: fall, femur, fracture, injury

\section{Introduction}

In recent years, there has been an increase in the size of the geriatric population worldwide because of improvements in health care and living standards in many countries. By the year 2030, approximately $25 \%$ of the population of Western countries will be in the geriatric age-group. ${ }^{1}$ In the US in $2010,13 \%$ of the population was aged $\geq 65$ years, and this age-group is the most rapidly growing part of the population. ${ }^{2}$ The incidence of many health problems is increased in the elderly, such as impairment of cognitive function, chronic diseases, and musculoskeletal disorders. ${ }^{3}$

A healthy and active lifestyle is increasingly feasible for the elderly, and may cause an increased risk of injury. ${ }^{4,5}$ The incidence of geriatric trauma that causes admission to emergency units is increasing with the increased size of the elderly population. The most frequent geriatric injuries occur from falls and cause minor orthopedic injury or morbidity. However, death associated with major trauma may also occur, and $28 \%$ of deaths related to trauma occur in people aged $\geq 65$ years. Concurrent disorders may increase the risk of complications. Although injury severity is typically less in older than younger people, the outcomes are worse in the elderly. ${ }^{6}$ It is important to define 
the causes of geriatric trauma to prevent injury and decrease morbidity, mortality, and associated costs. ${ }^{7}$

Geographic variation in trauma patterns may occur, but there is limited information available about geriatric trauma in Turkey. The purpose of the present study was to evaluate the mechanisms of trauma, clinical characteristics, and outcomes of elderly people admitted to an emergency unit in Turkey because of blunt trauma, and to define the factors that affect trauma severity. Describing these factors may help guide the development of precautions to limit blunt trauma in the elderly.

\section{Materials and methods Subjects}

This study was a retrospective review of patients aged $\geq 65$ years who were admitted to the Emergency Medicine Department of Selçuk University Medical Faculty, a tertiary health care hospital, between January 2011 and June 2013 because of trauma. During this period, there were 137,413 patients admitted to the emergency department of Selçuk University Medical Faculty, including 22,127 patients who had trauma, mostly blunt trauma. Patients aged $<65$ years were excluded from the study. The electronic database of the hospital showed 654 patients $(0.47 \%$ of all emergency department patients and $2.9 \%$ of all trauma patients) aged $\geq 65$ years who had trauma. Data were obtained from the hospital records, including sex, mechanism of trauma, injury site, body temperature, pulse, respiratory rate, Glasgow Coma Scale score, duration of hospital stay, final diagnosis, and clinical disposition. There were 86 patients who were excluded because of missing data in the medical records. The remaining 568 patients were included in the study. The study was approved by Selçuk University, Faculty of Medicine, Non-drug-using Clinical Research Ethics Committee.

\section{Statistical analysis}

Data analysis was performed with statistical software (SPSS for Windows, version 15.0; IBM Corporation, Armonk, NY,
USA). Comparisons were made with the $\chi^{2}$ test. Statistical significance was defined as $P \leq 0.05$.

\section{Results}

In the 568 patients in the study, there were more women than men (Table 1). Most patients had a low-energy fall, which was the most common cause of injury (Table 1). The mean temperature was $36^{\circ} \mathrm{C}$, pulse was 75 beats per minutes, respiratory rate was 17 breaths per minute, and Glasgow Coma Scale score was 14.7.

The cause of injury was significantly different between women and men; most low-energy falls occurred in women, and most high-energy falls occurred in men (Table 1). The most common anatomic site of injury was the lower extremity, and the most common fracture site was the femur (Table 2). Women had a significantly greater risk of upperextremity injury and forearm fracture than men; men had significantly greater risk of thoracic injury, spine injury, and rib fracture with or without pulmonary contusion than women (Table 2).

Most patients were discharged within 9 days after injury (Table 3). More patients had nonoperative treatment than surgery (Table 3 ). There was one patient who died in the emergency department, and 30 other patients who died during hospitalization (Table 3).

Injuries associated with an increased risk of being hospitalized included lower-extremity, thoracic, upperextremity, and spine injury, and femur, rib, and skull fractures (Table 4).

\section{Discussion}

The morphologic and physiologic changes observed in the elderly affect many organ systems and cause several disorders. Chronic disorders may increase the risk of falling because of reduced physical activity, muscle weakness, and imbalance. ${ }^{8}$ Falls are the major cause of disability and death from trauma in patients aged $>65$ years. ${ }^{9}$ Reduction in bone

Table I Causes of trauma in patients aged $\geq 65$ years who were evaluated in an emergency department in Konya, Turkey ( $n=568$ )

\begin{tabular}{|c|c|c|c|c|c|c|c|c|c|}
\hline \multirow{2}{*}{$\begin{array}{l}\text { Cause of } \\
\text { injury }^{\dagger}\end{array}$} & \multicolumn{3}{|c|}{ Women } & \multicolumn{3}{|c|}{ Men } & \multicolumn{3}{|c|}{ Total } \\
\hline & $\mathbf{n}$ & (\% women) & $\begin{array}{l}\text { (\% cause } \\
\text { of injury) }\end{array}$ & $\mathbf{n}$ & (\% men) & $\begin{array}{l}\text { (\% cause } \\
\text { of injury) }\end{array}$ & $\mathbf{n}$ & (\% total) & $\begin{array}{l}\text { (\% cause of } \\
\text { injury) }\end{array}$ \\
\hline Low-energy fall & 225 & $(72)$ & (59) & 154 & $(6 I)$ & (4I) & 379 & $(67)$ & $(100)$ \\
\hline Traffic accident & 41 & $(13)$ & (52) & 38 & (15) & $(48)$ & 79 & (14) & $(100)$ \\
\hline High-energy fall & 24 & (8) & (35) & 45 & (18) & (65) & 69 & (12) & $(100)$ \\
\hline Other $\ddagger$ & 24 & (8) & (59) & 17 & (7) & (4I) & 41 & (7) & $(100)$ \\
\hline Total & 314 & $(100)$ & (55) & 254 & $(100)$ & (45) & 568 & $(100)$ & $(100)$ \\
\hline
\end{tabular}

Notes: Mean age \pm standard deviation (age range), years: women, $75.8 \pm 7.0$ (65-98); men, 74.8 \pm 6.9 (65-93). Data reported as number (\% sex) (\% cause of injury). ${ }^{\dagger}$ Difference between women and men, $P \leq 0.002$; ;includes injuries from pounding, buckling, and contact with animals. 
Table 2 Relation between injury site and sex in patients aged $\geq 65$ years who were evaluated in an emergency department in Konya, Turkey ( $\mathrm{n}=568$ [3।4 women, 254 men])

\begin{tabular}{|c|c|c|c|c|c|c|}
\hline Injury site & Total & Women, n (\%) & Men, n (\%) & Odds ratio & ( $95 \%$ confidence interval) & $P \leq$ \\
\hline \multicolumn{7}{|l|}{ Anatomic site } \\
\hline Lower extremity & 230 & $137(60)$ & $93(40)$ & 0.7 & $(0.5-1.0)$ & NS \\
\hline Thorax & 91 & $33(36)$ & $58(64)$ & 2.5 & $(1.6-4.0)$ & 0.001 \\
\hline Upper extremity & 81 & $57(70)$ & $24(30)$ & 2.1 & $(1.3-3.5)$ & 0.003 \\
\hline Head & 67 & $32(48)$ & $35(52)$ & 1.4 & $(0.8-2.3)$ & NS \\
\hline Spine & 34 & $12(35)$ & $22(65)$ & 2.4 & $(1.5-4.9)$ & 0.02 \\
\hline Pelvis & 22 & $12(55)$ & $10(45)$ & 1 & $(0.4-2.4)$ & NS \\
\hline Abdomen & 6 & I (I7) & $5(83)$ & 6.3 & $(0.7-54.1)$ & NS \\
\hline \multicolumn{7}{|l|}{ Fracture site } \\
\hline Femur fracture & 206 & $123(60)$ & $83(40)$ & 0.8 & $(0.5-1.1)$ & NS \\
\hline $\begin{array}{l}\text { Rib fracture with or without } \\
\text { pulmonary contusion }\end{array}$ & 66 & $26(39)$ & $40(61)$ & 2.1 & $(1.2-3.5)$ & 0.006 \\
\hline Forearm fracture & 37 & $28(76)$ & $9(24)$ & 2.7 & $(1.2-5.8)$ & 0.01 \\
\hline Skull fracture & 26 & $13(50)$ & $13(50)$ & 1.2 & $(0.6-2.7)$ & NS \\
\hline
\end{tabular}

Abbreviation: NS, not significant.

density, imbalance, and reduction in reflexes may increase the frequency of falls and related problems. Postmenopausal hormonal changes impair calcium balance and increase the risk of osteoporosis. The frequency of fractures is increased in osteoporotic patients, and fractures necessitating hospitalization may be observed after falls. Frequency of falls also may be increased because of hypertension, cerebrovascular disease, diabetes mellitus, adverse reactions to drugs, syncope, unconsciousness, or orthostatic hypotension. ${ }^{10,11}$ In addition, patients who are discharged from hospital may be at increased risk of having falls and associated injuries. ${ }^{12}$ Therefore, the

Table 3 Disposition, hospitalization, and treatment in patients aged $\geq 65$ years who were evaluated in an emergency department in Konya, Turkey

\begin{tabular}{lll}
\hline Status & \multicolumn{2}{l}{ Patients, $\mathbf{n}(\%)$} \\
\hline Disposition after evaluation in emergency department & & \\
Hospitalized & 377 & $(66)$ \\
Discharged from emergency department & 140 & $(25)$ \\
$\begin{array}{l}\text { Discharged after observation period } \\
\text { in emergency department }\end{array}$ & 44 & $(8)$ \\
Transferred to other health facility & & \\
Died in emergency department & \\
Hospitalization & \\
Discharged within the first 3 days & 6 & $(1)$ \\
Hospitalized for 4-9 days & 1 & $(0)$ \\
Stayed in the hospital $\geq 10$ days & 112 & $(30)$ \\
Treatment & 187 & $(50)$ \\
Nonoperative & 78 & $(20)$ \\
Surgery & & \\
Transferred to other health facility & 288 & $(51)$ \\
Died & 243 & $(43)$ \\
\hline
\end{tabular}

Notes: ${ }^{\dagger}$ Cause of death hemorrhagic shock; ${ }^{\ddagger} \mathrm{n}=377$ patients who were hospitalized (six patients were transferred to other health facilities from the emergency department); *includes I patient who died in the emergency department. frequency of trauma-related admissions to emergency departments in the elderly is increasing. Many $(11 \%)$ admissions to emergency departments involve patients aged $\geq 65$ years, and the frequency of admissions is expected to increase to $40 \%$ in the coming decades. ${ }^{13}$ Minor orthopedic injury or morbidity may occur because of a fall, which is the most frequent cause of geriatric trauma, and death associated with major trauma may also occur. ${ }^{14,15}$ In people aged $\geq 65$ years, trauma is a frequent cause of death, with $25 \%-28 \%$ of deaths related to trauma. ${ }^{13,16}$

Risk factors observed in the elderly may increase the frequency of falls. Approximately $50 \%$ people aged $\geq 60$ years may have had a previous fall, and $23.8 \%$ people aged $\geq 60$ years may have had a fall within the previous 6 months. ${ }^{17,18}$ In developed countries, geriatric trauma is most frequently associated with traffic accidents and falls. In Turkey, falls are the most frequent cause of geriatric injury, as noted in the present study (Table 1). Falls may include slipping from a higher to a lower level because of carelessness, without any pushing force, syncope, or stroke. ${ }^{19,20}$ Low- or high-energy falls caused emergency department admission in 448 patients (79\%) in the present study (Table 1). Traffic accidents were the second most frequent cause of admission to the emergency department (Table 1).

Morbidity and mortality associated with falls are higher in the elderly than the young population. The frequency of trauma-related death in the hospital is $15 \%-30 \%$ in the elderly and $4 \%-8 \%$ in the young population. ${ }^{21}$ In the elderly, the effects of trauma may decrease an active lifestyle and physiologic capacity. ${ }^{22,23}$ Morbidity may be observed with falls from standing or sitting. Therefore, prevention 
Table 4 Relation between injury site and hospitalization in patients aged $\geq 65$ years who were evaluated in an emergency department in Konya, Turkey $(\mathrm{n}=56 \mathrm{I})$

\begin{tabular}{|c|c|c|c|c|c|c|}
\hline Injury site & Total & $\begin{array}{l}\text { Hospitalized, } \\
\text { n (\%) }\end{array}$ & $\begin{array}{l}\text { Discharged from emergency } \\
\text { department, } n(\%)\end{array}$ & Odds ratio & $\begin{array}{l}\text { (95\% confidence } \\
\text { interval) }\end{array}$ & $P \leq$ \\
\hline \multicolumn{7}{|l|}{ Anatomic site } \\
\hline Lower extremity & 228 & $218(96)$ & $10(4)$ & 14 & $(7.1-27.3)$ & 0.001 \\
\hline Thorax & 86 & $82(95)$ & $4(5)$ & 8.2 & $(3.0-22.9)$ & 0.001 \\
\hline Upper extremity & 81 & $4 I(5 I)$ & $40(49)$ & 0.3 & $(0.2-0.4)$ & 0.001 \\
\hline Head & 65 & $51(78)$ & $14(22)$ & 1.2 & $(0.7-2.4)$ & NS \\
\hline Spine & 33 & $31(94)$ & $2(6)$ & 5.5 & $(1.3-23.2)$ & 0.01 \\
\hline Pelvis & 21 & $19(90)$ & $2(10)$ & 3.3 & $(0.8-14.2)$ & NS \\
\hline Abdomen & 5 & $5(100)$ & $0(0)$ & 0.7 & $(0.7-0.8)$ & NS \\
\hline \multicolumn{7}{|l|}{ Fracture site } \\
\hline Femur fracture & 205 & $200(98)$ & $5(2)$ & 24.4 & $(9.8-60.9)$ & 0.001 \\
\hline $\begin{array}{l}\text { Rib fracture with or without } \\
\text { pulmonary contusion }\end{array}$ & 62 & $59(95)$ & $3(5)$ & 7.4 & $(2.3-24.1)$ & 0.001 \\
\hline Forearm fracture & 37 & $17(46)$ & $20(54)$ & 0.3 & $(0.1-0.5)$ & 0.001 \\
\hline Skull fracture & 24 & $23(96)$ & I (4) & 8 & $(1.1-60.0)$ & 0.02 \\
\hline
\end{tabular}

Notes: Of the $56 \mathrm{I}$ patients, 377 were hospitalized, 44 discharged after observation period in emergency department, and I 40 discharged (does not include six other patients who were transferred to other health facilities and one patient who died in the emergency department).

Abbreviation: NS, not significant.

of trauma may decrease morbidity and mortality in the elderly. ${ }^{23}$

In the present study, high-energy falls were less common than low-energy falls (Table 1). ${ }^{21}$ Trauma associated with low-energy falls was more frequent in women than men aged $\geq 65$ years (Table 1). ${ }^{24}$ In contrast, high-energy falls were more frequent in men than women (Table 1). In addition, men had a higher frequency of thoracic and spinal trauma than women (Table 2), likely because men in this geographic region may have a more active lifestyle than women aged $\geq 65$ years. Minor trauma (upper-extremity trauma and forearm fracture) was more frequent in women (Table 2), who typically prefer to stay at home.

In the present study, there were more women than men who had trauma-related admissions to the emergency department (Table 1). Some previous studies showed a higher frequency of falls in women, but others showed a higher frequency of falls in men..$^{20,25,26}$ Variation in lifestyle habits between people may affect the different patterns of trauma in different studies.

Previous studies showed that the extremities, head, and neck may be the most common sites of injury. ${ }^{19,27}$ In the present study, trauma was most common in the extremities, thorax, and head (Table 2). The higher frequency of lower- than upper-extremity trauma in the present study may have occurred because our hospital is a regional university hospital, and we frequently receive referrals of many elderly patients who have kidney failure, cerebrovascular disease, or cardiovascular disease, and who cannot have surgery because of the high risk of complications. In elderly patients, rib, pelvis, and femur fractures are more frequent than in younger patients, and age is an important factor that increases the risk of developing trauma-related complications. ${ }^{24}$ In the present study, the most common site of extremity fracture was the femur (Table 2). We did not evaluate the effect of age on morbidity and mortality, because we did not compare younger and older patients. Mortality may occur in $6.4 \%$ of elderly patients with trauma-related admissions, ${ }^{28}$ and there were 31 deaths in 568 patients $(5.5 \%)$ in the present study. Age alone is an independent risk factor for trauma-related mortality. ${ }^{23}$

A previous study showed that risks of trauma-related hospitalization were increased 7.45-fold after skull fracture, 10.67-fold after pelvis fracture, 10.24-fold after femur fracture, and 16.09-fold after vertebral fracture. ${ }^{24}$ In the present study, trauma-related hospitalization was increased 24.4-fold after femur fracture, 8.2-fold after thoracic trauma, eightfold after skull fracture, and 5.5-fold after spinal trauma (Table 4). In these two studies, femur fracture markedly increased the risk of hospitalization, possibly because femur trauma from falls is common in the elderly, and most hip fractures are treated with orthopedic surgery.

Limitations of the present study include the absence of a younger patient group aged $<65$ years for comparative evaluation of the effect of age on morbidity and mortality. The study was a retrospective study using previous patient records, and the effect of comorbidities or drugs on patient outcome could not be evaluated because of insufficient data. 
In conclusion, the elderly population is growing in Turkey because of improvements in quality of life. In addition, the number of admissions to hospitals because of trauma in the elderly is increasing. The most frequent cause of trauma in the elderly is low-energy trauma, and the extremities are the most common site of injury (Tables 1 and 2). Fractures in the elderly are common. It is important to prevent situations such as falls that may cause trauma and to provide adequate treatment for complications after falls.

\section{Author contributions}

Hasan Kara, Aysegul Bayir, and Ahmet Ak participated in the design of the study; Necmettin Tufekci, Murat Akinci, and Melih Azap acquired the data; Hasan Kara, Selim Degirmenci, and Murat Akinci analyzed the data; Aysegul Bayir, Necmettin Tufekci, and Melih Azap wrote the manuscript; and Hasan Kara, Ahmet Ak, and Selim Degirmenci revised the manuscript. All the authors read and approved the final manuscript.

\section{Disclosure}

The authors report no conflicts of interest in this work.

\section{References}

1. Bergeron E, Clement J, Lavoie A, et al. A simple fall in the elderly: not so simple. J Trauma. 2006;60:268-273.

2. US Census Bureau. 2010 Census briefs. 2012. Available from: http://www. census.gov/population/www/cen2010/glance/files/2010CensusBriefs. pdf. Accessed November 13, 2013.

3. Saka B, Özkulluk H. Evaluation of the nutritional status and relationship of malnutrition with other geriatric syndromes in elderly patients who admitted to the internal medicine outpatient clinic. Gulhane Med J. 2008;50(3):151-157.

4. Mann NC, Chan RM, Mullins RJ, Brand DM, Jurkovich GJ. Survival among injured geriatric patients during construction of a statewide trauma system. J Trauma. 2001;50:1111-1116.

5. Jacobs DG. Special considerations in geriatric injury. Curr Opin Crit Care. 2003;9:535-539.

6. Oreskovich MR, Howard JD, Copass MK, Carrico CJ. Geriatric trauma: injury patterns and outcome. J Trauma. 1984;24:565-572.

7. Atilla Ö, Çalışkan F, Aksay E, Doğan T, Eyler Y, Akın Ş. Clinical Factors in Geriatric Blunt Trauma. Tr J Emerg Med. 2012;12(3):123-128.

8. Lawlor DA, Patel R, Ebrahim S. Association between falls in elderly women and chronic disease and drug use: cross sectional study. BMJ. 2003;327:1-6.

9. Hester AL, Wei F. Falls in the community: state of the science. Clin Interv Aging. 2013;8:675-679.
10. Alexander BH, Rivara FP, Wolf ME. The cost and frequency of hospitalization for related-injuries in older adults. Am J Public Health. 1992;82:1020-1023.

11. Ferrera P, Bartfield J, D'Andrea C. Geriatric trauma: outcomes of elderly patients discharged from the ED. Am J Emerg Med. 1999;17: 629-632.

12. Hill AM, Hoffmann T, Haines TP. Circumstances of falls and fallsrelated injuries in a cohort of older patients following hospital discharge. Clin Interv Aging. 2013;8:765-774.

13. Blumenthal J, Plummer E, Gambert S. Trauma in the elderly: causes and prevention. Clin Geriatr. 2010;8:21-24.

14. Ma OJ, Meldon SW. Geriatric trauma. In: Tintinalli JE, Kelen GD, Stapczynski JS, editors. Emergency Medicine: A Comprehensive Study Guide. 6th ed. New York: Mcgraw-Hill; 2004:1549-1553.

15. Jacobs DG, Plaisier BR, Barie PS, et al. Practice management guidelines for geriatric trauma: the EAST Practice Management Guidelines Work Group. J Trauma. 2003;54:391-416.

16. Akköse AS, Bulut M, Fedakar R, Ozgürer A, Ozdemir F. Trauma in the elderly patients in Bursa. Ulus Travma Acil Cerrahi Derg. 2006;12:230-234.

17. Yeşilbalkan ÖU, Karadakovan A. The Frequency of falls in elderly individuals living in Narlidere Rest Home and the evulation of the affecting factors. Turk J Geriatr. 2005;8(2):72-77.

18. Wright AS, Schurr MJ. Geriatric trauma: review and recommendations. WMJ. 2001;100:57-59.

19. Adam SH, Eid HO, Barss P, et al. Epidemiology of geriatric trauma in United Arab Emirates. Arch Gerontol Geriatr. 2008;47:377-382.

20. Işı1k AT, Cankurtaran M, Doruk H, Mas MR. Evaluation of falls in geriatric patients. Turk J Geriatr. 2006;9(1):45-50.

21. Mandavia D, Newton K. Geriatric trauma. Emerg Med Clin North Am. 1998;16:257-274.

22. Iaria M, Surleti S, Famá F, Villari SA, Gioffré-Florio M. Epidemiology and outcome of multiple trauma in the elderly population in a tertiary care hospital in Southern Italy. BMC Geriatr. 2009;9 Suppl 1:A69.

23. Taylor MD, Tracy JK, Meyer W, Pasquale M, Napolitano LM. Trauma in the elderly: intensive care unit resource use and outcome. J Trauma. 2002;53:407-414.

24. Ekci B, Aktaş C, Eren SH, Sarıkaya S. Consequences of low energy falls in patients aged 65 years and over and those under 65 years. Turk J Geriatr. 2010;13:185-190.

25. Aktaş C, Eren SH, Eryılmaz M. Effects of co-morbid disease and drug consumption on trauma patients 65 years of age and older: a university emergency department experience. Ulus Travma Acil Cerrahi Derg. 2008; $14: 313-317$.

26. Güneytepe U, Aydın S, Gökgöz S, Ozgüç H, Ocakoçlu G, Aktaş H. The factors influencing the mortality in elderly trauma patients and scoring systems. Uludă̆ Medical Journal. 2008;34:15-19.

27. Gowing R, Jain MK. Injury patterns and outcomes associated with elderly trauma victims in Kingston, Ontario. Can J Surg. 2007;50:437-444.

28. Yildiz M, Bozdemir MN, Kiliçaslan I, et al. Elderly trauma: the two years experience of a university-affiliated emergency department. Eur Rev Med Pharmacol Sci. 2012;16 Suppl 1:62-67.
Clinical Interventions in Aging

\section{Publish your work in this journal}

Clinical Interventions in Aging is an international, peer-reviewed journal focusing on evidence-based reports on the value or lack thereof of treatments intended to prevent or delay the onset of maladaptive correlates of aging in human beings. This journal is indexed on PubMed Central, MedLine, the American Chemical Society's 'Chemical Abstracts Ser-

\section{Dovepress}

vice' (CAS), Scopus and the Elsevier Bibliographic databases. The manuscript management system is completely online and includes a very quick and fair peer-review system, which is all easy to use. Visit $\mathrm{http}: / / \mathrm{ww}$.dovepress.com/testimonials.php to read real quotes from published authors. 